\title{
EFFECT OF ROOT-SOIL PARAMETERS ON THE LODGING RESISTANCE OF SUGARCANE (SACCHARUM OFFICINARUM L.)
}

\author{
YANG, W. $.^{1,2}-$ YUAN, F. W. ${ }^{1}-$ CHEN, Y. Q. ${ }^{3}-$ YANG, J. $^{1 *}$ \\ ${ }^{I}$ College of Mechanical Engineering, Guangxi University, Nanning 530004, China \\ ${ }^{2}$ Guangxi Key Laboratory of Manufacturing System \& Advanced Manufacturing Technology, \\ College of Mechanical Engineering, Guangxi University, Nanning 530004, China \\ ${ }^{3}$ Xingjian College of Science and Liberal Arts, Guangxi University, Nanning 530005, China \\ *Corresponding author \\ e-mail: gxuyangjian@163.com \\ (Received $8^{\text {th }}$ Nov 2019; accepted $3^{\text {rd }}$ Jul 2020)
}

\begin{abstract}
Lodging reduce sugarcane yield, also results in the increase of harvest loss and head-splitting rate in mechanical harvesting. Although there are some researches on lodging resistance of sugarcane, there are few studies on the effects of root-soil multi-factor, which limits the discovery of the most important lodging resistance influence factors and the most effective lodging resistance technical measure of sugarcane. This study aimed at: (1) establishing the mathematical model of the relationship between $F_{30^{\circ}}$ and the root and soil parameters using the artificially induced tilt experiment for sugarcane. $F_{30^{\circ}}$ is the maximum pulling force in the process of the tilt angle (the angle between stem and ground) changing from $90^{\circ}$ to $30^{\circ}$; (2) studying the effects of lodging resistance using the model. The results show that the established model is reasonable. The two most important influence factors of sugarcane lodging resistance are number of roots and interaction between planting depth and soil hardness. The most effective measure to improve the lodging resistance is to increase the number of roots through breeding and reasonable fertilization, and to increase the planting depth, meanwhile, to establish good drainage measures to timely drain water in typhoon season for reducing soil moisture and maintaining greater soil hardness.
\end{abstract}

Keywords: tilt induction test, multi-factor, mathematical model, influence law, lodging resistance technical measure

\section{Introduction}

Lodging reduces crop yields (Goodman and Ennos, 1999; Berry et al., 2000; Terashima et al., 2003; Sposaro et al., 2008; Loades et al., 2013; Manzur et al., 2014; Bian et al., 2018; Liu et al., 2018; Wu and Ma, 2018). And sugarcane (Saccharum officinarum L.) is the main sugar material in the world and China, of which, the sugarcane planting area in the world is about 26 million ha, China's sugarcane planting area is about 1.6 million ha (Li et al., 2017, 2019; Wang and Zhang, 2018). Lodging normally reduce sugarcane yield by $10-20 \%$, and when lodging is serious, the yield can even be reduced by more than 50\% (Singh et al., 2002; van Heerden et al., 2015). Meanwhile, lodging also results in the increase of harvest loss and head-splitting rate in mechanical harvesting of sugarcane (Wang et al., 2010; Ou et al., 2013). And because of its high growth height, sugarcane is more prone to lodging. Thus, it is necessary to study the lodging resistance of sugarcane. Berding and Hurney (2005) conducted the comparison tests of sugarcane planting with different planting depths and varieties. The result showed that lodging in a planting depth of $260 \mathrm{~mm}$ was lower than that in a depth of $120 \mathrm{~mm}$. Lodging of sugarcane variety Q152 was less than that of sugarcane varieties Q187 and Q174. Babu et al. (2009) investigated the relationship between the hardness 
of sugarcane skin and lodging by experiment. The result showed that the sugarcane was not prone to lodge when the hardness of sugarcane skin was high. Loganandhan et al. (2013) conducted the comparison tests of sugarcane planting with different planting depths and hilling conditions. The result showed that lodging could be diminished at a high planting depth and hilling thickness. Jongrungklang et al. (2018) studied the effects of stalk height, stalk diameter, leaf and stalk weight, root length density (RLD), root length density percentage (\% RLD) on lodging of sugarcane. The results showed that high stalk dry weight is a key factor that induces lodging. The low stalk heights and stalk dry weights as well as a good partition of the root in the upper soil layer had better lodging resistance. The cultivars with large root systems in the upper soil layer should be selected in breeding for strong lodging resistance. Li et al. (2019) studied the lodging grade, fracture resistance force, basal stem diameter, middle stem diameter and brix. With the data of lodging classification, the lodging resistance index was established. The results showed that the lodging resistance index was significantly and positively correlated with the ratio of basal and middle stem diameters and brix. These authors carried out some researches on lodging resistance of sugarcane. However, there are few studies on the effects of root-soil multi-factor on the lodging resistance, which limits the discovery of the most important lodging resistance influence factors and the most effective lodging resistance technical measure of sugarcane.

The root system of sugarcane is composed of main stem and root, and its morphological structure is complex. The root system of newly planted sugarcane studied in this paper is shown in Figure 1. Meanwhile, the root plate (the soil-root volume that rotates in the broader soil matrix when lodging occurs) which has large influence on lodging is closely associated with the complex root and soil parameters (Sposaro et al., 2008). It is difficult to study the effect of lodging resistance by mechanical analysis alone. The objectives of the work presented here were to establish the mathematical model of the effect of root and soil parameters on lodging resistance using field experiments and regression analysis method, and to study the influence law and mechanism of root-soil parameters on the lodging resistance. The study outcomes will discover the most important lodging resistance influence factors and the most effective lodging resistance technical measure of sugarcane.

\section{Materials and methods}

\section{Lodging resistance measurements}

\section{Test scheme and method}

The lodging resistance of sugarcane is associated with the length, the diameter, the density, the tensile strength of sugarcane roots, the planting depth of sugarcane, the complex soil parameters (including density, cohesion, moisture content, internal friction angle, elastic modulus, etc.) and the comprehensive friction coefficient between sugarcane roots and soil. And the comprehensive friction coefficient between roots and soil is closely related to soil water content that significantly associate with soil hardness which is a comprehensive index to measure the properties of soil (Ren, 2011). Thus, the number of roots $\mathrm{x}_{1}$, the length of roots $\mathrm{x}_{2}$, the diameter of roots $\mathrm{x}_{3}$, the planting depth of sugarcane $\mathrm{x}_{4}$, the tensile strength of roots $\mathrm{x}_{5}$ and the soil hardness $\mathrm{x}_{6}$ were selected as experimental factors. 
Strong lodging resistance of sugarcane required large wind load to produce the same tilting angle. Therefore, the wind load that makes sugarcane produce the same tilting angle can be regard as a measuring index of lodging resistance. However, it is difficult for different sugarcane to produce the same tilting angle by controlling wind load in field test. And the distributed wind load acting on sugarcane can be replaced by a concentrated load. Hence the test of sugarcane lodging resistance under wind load can be replaced by the artificially induced tilting experiment of sugarcane applying the pulling force (Manzur et al., 2014). Meanwhile, when the tilting angle (i.e., the angle between stem and ground) is $30^{\circ}$, it indicates that a severe lodging occurs (Mou et al., 2010). Thus, $F_{30^{\circ}}$ was taken as the test index. $F_{30^{\circ}}$ is the maximum pulling force in the process of the tilt angle changing from $90^{\circ}$ to $30^{\circ}$.

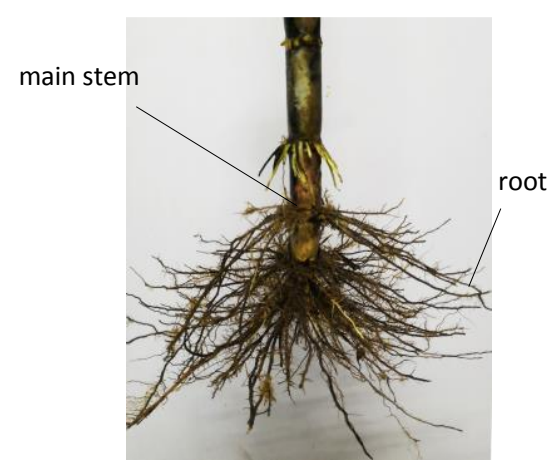

Figure 1. Sugarcane root system

When loading height and loading speed on the stem are different, the corresponding required pulling forces for producing the same tilting angle are different. Nevertheless, the effect of root and soil parameters on lodging resistance is not changed. Thus, to facilitate the operation of the test, the loading height of the pulling force set at $0.5 \mathrm{~m}$ above the ground, and the pulling force was applied slowly and uniformly. Meanwhile, the upper part of the sample sugarcane was removed for reducing the influence of gravity, and only $0.6 \mathrm{~m}$ of the stem was retained. Guangxi Province is main sugarcane production base in China, and its planting area accounts for more than $60 \%$ of China. Thus, in order to obtain the representative experiment results, the sugarcane with well growth, no pests and no diseases were randomly selected in different main sugarcane producing areas of Guangxi, China for the experiment. The number of test sites is 3 , and the number of samples taken per sites is 15 . The number of verifying test sites is 2 , and the number of samples taken per sites is 4 . The easy lodging period of sugarcane in Guangxi is from July to September. During this period, the root growth is different due to the different length of growth time, but it does not change the influence of root parameters on lodging resistance. Therefore, the sugarcane tilting tests were carried out from July to September in this paper.

Simultaneously, in order to obtain soil water content in the monsoon and typhoon days, artificial irrigation was carried out before the tilting experiment. During irrigation, the soil wall with a radius of about $1 \mathrm{~m}$ was built around the sample sugarcane, and then water was filled into the wall. Moreover, in order that water can permeate downward sufficiently, the experiments were carried out after filling the water for $24 \mathrm{~h}$.

After the experiments, the root system of sugarcane was dug out and the planting depth of sugarcane was measured. And then the soil on the root system was washed 
away with water, and the number, average length and diameter of roots were obtained. Finally, eight roots were randomly selected for measuring the tensile strength, and then their average value was taken as the tensile strength of individual sugarcane roots. Tensile strength test of the roots was performed using the electronic universal testing machine. To avoid root damage caused by clamping parts, the gauze was used to wind round the both ends of root. The measurement of the soil hardness and the tilt induction test were carried out simultaneously. The measured soil located near the sugarcane sample. Because the soil hardness is closely related to the soil depth (Yang et al., 2015), the soil hardness was measured in three layers according to the planting depth. Twelve test points were selected in each layer, and then the average hardness value of all test points in three layers was taken as the soil hardness.

The higher the prediction accuracy of the established mathematical model, the more induction tests are needed. However, the tilt induction test of each sugarcane needs a lot of time, thus, after comprehensive consideration, 45 sugarcane samples were selected for the test. The experimental scheme and results are shown in Table Al in the Appendix.

\section{Test equipment and site}

The main test equipment are as follows: self-made inducing sugarcane tilt test system, electronic tension meter, hardness tester, NKK-4005 microcomputer-controlled electronic universal testing machine (Shenzhen Nanfangjinke Instruments and Equipment Co., Ltd., China, the maximum load is $5 \mathrm{kN}$ and the load resolution is $0.1 \mathrm{~N}$ ), electronic balance, oven and protractor, etc. The tilt induction test system of sugarcane is shown in Figure 2.

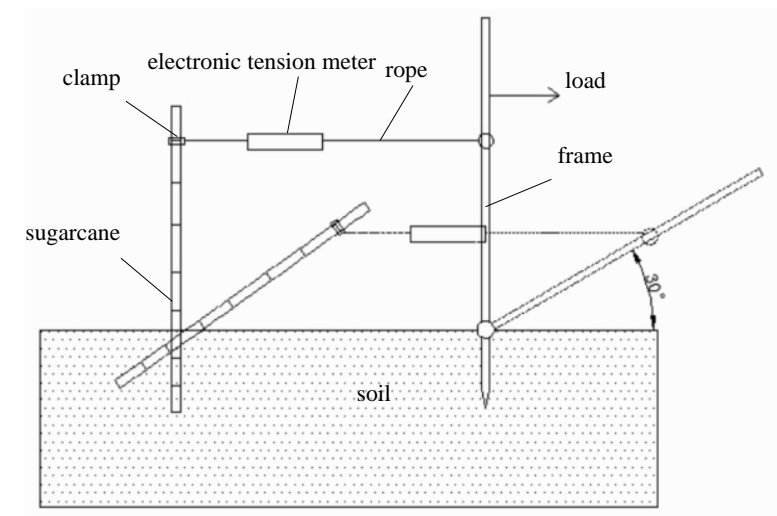

Figure 2. The tilt induction test system of sugarcane

The test sites and the sugarcane varieties are as follows:

(1) The sugarcane planting base is in Jinguang Farm, Nanning City, Guangxi Province, China (lat. $22^{\circ} 56^{\prime} 48.03^{\prime \prime} \mathrm{N}$, long. $107^{\circ} 53^{\prime} 43.25^{\prime \prime} \mathrm{E}$ ). The soil type is yellow clay. The sugarcane varieties are GT-32, GT-42, GT-46, Liucheng 07-150 and GT-22, respectively. The sugarcanes were planted in wide and narrow row alternately using machine. The wide row spacing is $1.2 \mathrm{~m}$ and the narrow row spacing is $0.5 \mathrm{~m}$. The sugarcanes were covered by film. The planting time was from January to February 2017. 3 sugarcane was chosen in each variety, and test time is July 2017. The total number of the samples was 15 . 
(2) The sugarcane planting base is in Qianwei Farm, Nankang Town, Beihai City, Guangxi Province, China (lat. $21^{\circ} 35^{\prime} 47.39^{\prime \prime} \mathrm{N}$, long. $109^{\circ} 28^{\prime} 46.49^{\prime \prime} \mathrm{E}$ ). The soil type is sandy soil. The sugarcane varieties are GT-46, GT-22, 03-23, GY-1 and Liucheng 05136, respectively. The sugarcanes were planted in the same row using machine. The row spacing is $1 \mathrm{~m}$. The sugarcanes were covered by film. The planting time was from January to February 2017. 3 sugarcane was chosen in each variety, and test time is August 2017. The total number of the samples was 15.

(3) The sugarcane planting base is in Guizhong Farm, Liuzhou City, Guangxi Province, China (lat. $24^{\circ} 29^{\prime} 17.12^{\prime \prime} \mathrm{N}$, long. $109^{\circ} 40^{\prime} 11.93^{\prime \prime} \mathrm{E}$ ). The soil type is loam. The sugarcane varieties are YT 94-128, GT-22, Liucheng 05-136, ROC 22 and GT-41, respectively. The sugarcanes were planted in wide and narrow row alternately using machine. The wide row spacing is $1.3 \mathrm{~m}$ and the narrow row spacing is $0.5 \mathrm{~m}$. Trickle irrigation was used in the middle of the narrow row. The sugarcanes were covered by film. The planting time was February 2017. 3 sugarcane was chosen in each variety, and test time is September 2017. The total number of the samples was 15.

The test sites in this paper have been marked on the map, as shown in Figure 3.

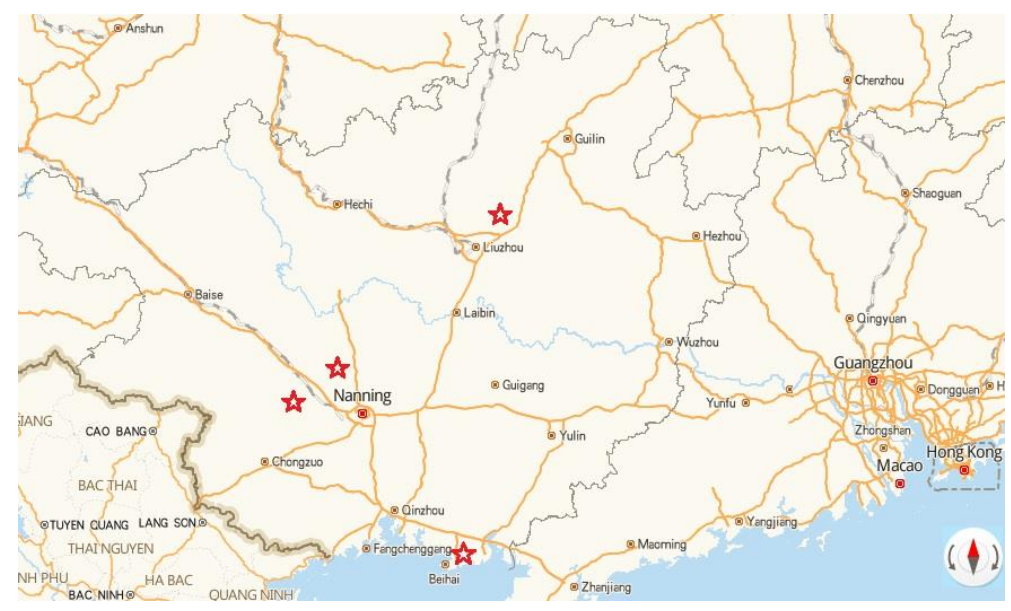

Figure 3. The map with location of test sites

\section{Regression analysis}

SPSS software is a powerful and mature mathematical statistics software. Therefore, using this software, regression analysis of the test data in Table Al was implemented, and the mathematical model of the relationship between $F_{30^{\circ}}$ and root-soil experiment factors was established. Meanwhile, using the software's significance test function, the mathematical model and regression coefficients were tested, and the significance of the mathematical model and the order of the influence of the experimental factors on $F_{30^{\circ}}$ were analyzed.

\section{Verification of mathematical model}

Firstly, $F_{30^{\circ}}$ was measured by the artificial induced tilt test, meanwhile, the parameters of soil hardness and sugarcane root were obtained by the above soil and root measurement methods. Then the predicted values of $F_{30^{\circ}}$ were calculated by substituting the parameters of soil hardness and root into the established mathematical model. Finally, the rationality of the mathematical model was verified by comparing the 
measured and predicted values of $F_{30^{\circ}}$. The sugarcane planting bases for verification are in Jinguang Farm, Nanning City, Guangxi Province, China (lat. 22 $56^{\prime} 48.03^{\prime \prime} \mathrm{N}$, long. $\left.107^{\circ} 53^{\prime} 43.25^{\prime \prime} \mathrm{E}\right)$ and Wuming County, Nanning City, Guangxi Province, China (lat. $23^{\circ} 13^{\prime} 12.89^{\prime \prime} \mathrm{N}$, long. $108^{\circ} 07^{\prime} 59.43^{\prime \prime} \mathrm{E}$ ). In the two bases, the soil types are yellow clay and red clay, and the sugarcane varieties are GT-32 and ROC 22, respectively. The sugarcanes were planted alternately in wide and narrow row using machine. The wide row spacing is $1.2 \mathrm{~m}$ and the narrow row spacing is $0.5 \mathrm{~m}$. The sugarcanes were covered by film. The planting time was March 2018. The experiment time was September 2018. 4 sugarcane with no pests were randomly selected in each variety for the verified tests.

\section{Factor influence analysis}

Using the established mathematical model, the relationships between significant factors or factor interactions and $F_{30^{\circ}}$ were obtained, and the influence laws of factors or factor interactions on $F_{30^{\circ}}$ were analyzed. Meanwhile, combined with observation in the experiment and relevant theoretical analysis, the influence mechanisms of factors or factor interactions on $F_{30^{\circ}}$ were discussed. When analyzing the relationships between a certain factor or factor interaction and $F_{30^{\circ}}$, except for the factor or factors considered, all other factors were average in the mathematical model.

\section{Results}

\section{Regression analysis}

The mathematical model of the relationship between $F_{30^{\circ}}$ and root-soil experiment factors is as follows.

$$
\begin{aligned}
& F_{30^{0}}=-188.976+1.43 x_{1}+2.355 x_{2}+76.044 x_{3}+9.587 x_{5} \\
& -0.042 x_{1} x_{4}-0.057 x_{1} x_{5}+0.13 x_{1} x_{6}-57.352 x_{3} x_{6}+5.656 x_{4} x_{6}
\end{aligned}
$$

where $x_{1}$ is number of roots, $x_{2}$ is root length, $x_{3}$ is root diameter, $x_{4}$ is planting depth, $x_{5}$ is tensile strength of root, and $x_{6}$ is soil hardness. The significance test results of the mathematical model and regression coefficients demonstrate that the mathematical model is significant at the level of 0.0001, and the regression coefficients are also significant at the level of 0.04-0.0001. The mathematical model is highly significant and fits well. Meanwhile, the significance test of the regression coefficients indicates that the order of factors affecting $F_{30^{\circ}}$ (lodging resistance of sugarcane) is number of roots and interaction between planting depth and soil hardness, root diameter and interaction between root diameter and soil hardness and interaction between number of roots and planting depth, tensile strength of root, interaction between number of roots and tensile strength of root, root length, interaction between number of roots and soil hardness.

\section{Verification of mathematical model}

The measured results of field validation tests and the predicted results according to Equation 1 are shown in Table 1. Table 1 shows that the minimum relative error between the predicted and the measured value is $5.9 \%$, while the maximum is $15.8 \%$, and the average relative error is $10.7 \%$. The main existence reason of error is that the 
root growth shape and soil structure are complex, and some factors could not be considered. The mathematical model is reasonable and can be used for analyzing lodging resistance of sugarcane.

Table 1. Measured and predicted results

\begin{tabular}{c|c|c|c|c|c|c|c|c|c}
\hline $\begin{array}{c}\text { Test } \\
\text { number }\end{array}$ & $\begin{array}{c}\text { Number } \\
\text { of roots } \\
\boldsymbol{x}_{\mathbf{1}} / \mathbf{b a r}\end{array}$ & $\begin{array}{c}\text { Root } \\
\text { length } \\
\boldsymbol{x}_{\mathbf{2}} / \mathbf{c m}\end{array}$ & $\begin{array}{c}\text { Root } \\
\mathbf{d i a m e t e r} \\
\boldsymbol{x}_{\mathbf{3}} / \mathbf{m m}\end{array}$ & $\begin{array}{c}\text { Planting } \\
\mathbf{d e p t h} \\
\boldsymbol{x}_{\mathbf{4}} / \mathbf{c m}\end{array}$ & $\begin{array}{c}\text { Tensile } \\
\text { strength of root } \\
\boldsymbol{x}_{\mathbf{5}} / \mathbf{M P a}\end{array}$ & $\begin{array}{c}\text { Soil } \\
\text { hardness } \\
\boldsymbol{x}_{\mathbf{6}} / \mathbf{1 0}^{-\mathbf{1}} \mathbf{M P a}\end{array}$ & $\begin{array}{c}\text { Predicted } \\
\text { maximum pulling } \\
\text { force } \\
\boldsymbol{F}_{\mathbf{3 0}} / \mathbf{N}\end{array}$ & $\begin{array}{c}\text { Measured } \\
\text { maximum pulling } \\
\text { force } \\
\boldsymbol{F}_{\mathbf{3 0}} / \mathbf{N}\end{array}$ & $\begin{array}{c}\text { Relative } \\
\text { error/\% }\end{array}$ \\
\hline 1 & 62 & 7.78 & 1.8 & 17.5 & 10.95 & 1.49 & 81.27 & 68.4 & 15.8 \\
2 & 56 & 7.44 & 1.68 & 14.2 & 11.3 & 1.29 & 63.95 & 59.6 & 6.8 \\
3 & 94 & 8.51 & 1.98 & 16.5 & 9.05 & 2.61 & 68.27 & 75.3 & 10.3 \\
4 & 108 & 8.81 & 1.82 & 16 & 6.73 & 1.16 & 75.31 & 63.6 & 15.5 \\
5 & 103 & 11.01 & 2.04 & 17 & 8.26 & 0.84 & 90.26 & 84.9 & 5.9 \\
6 & 114 & 10.17 & 2.28 & 15.8 & 12.15 & 1.88 & 83.29 & 91.7 & 10 \\
7 & 100 & 9.41 & 2.14 & 19.5 & 10.64 & 2.42 & 99.73 & 87.6 & 12.1 \\
8 & 127 & 8.8 & 1.78 & 17.5 & 8.23 & 1.26 & 91.58 & 83.3 & 9 \\
\hline
\end{tabular}

\section{Influence factor analysis}

\section{Single factor influence}

The relationships between $F_{30^{\circ}}$ and factors are shown in Figure 4.

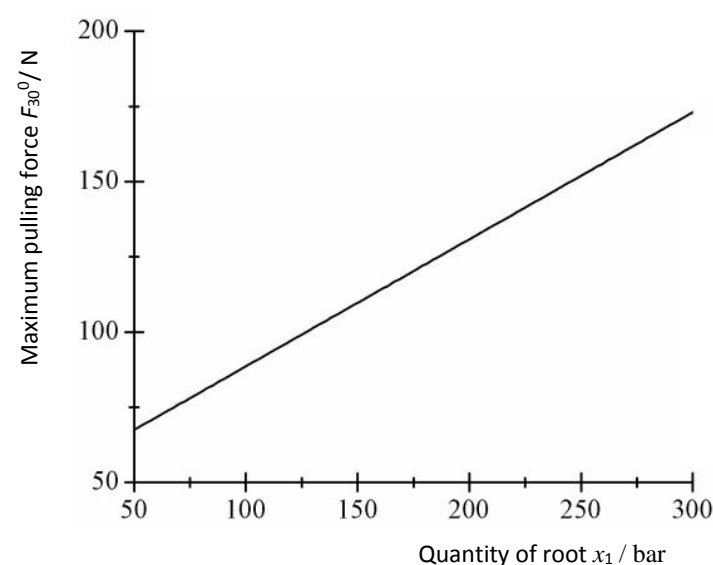

(a)

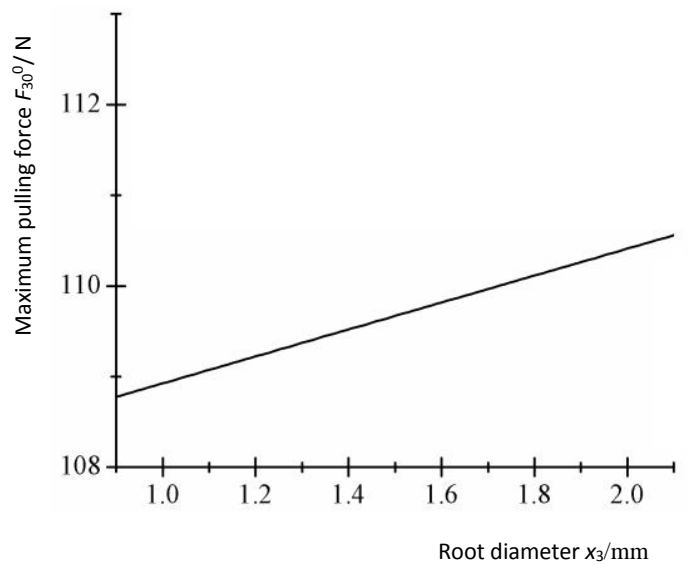

(c)

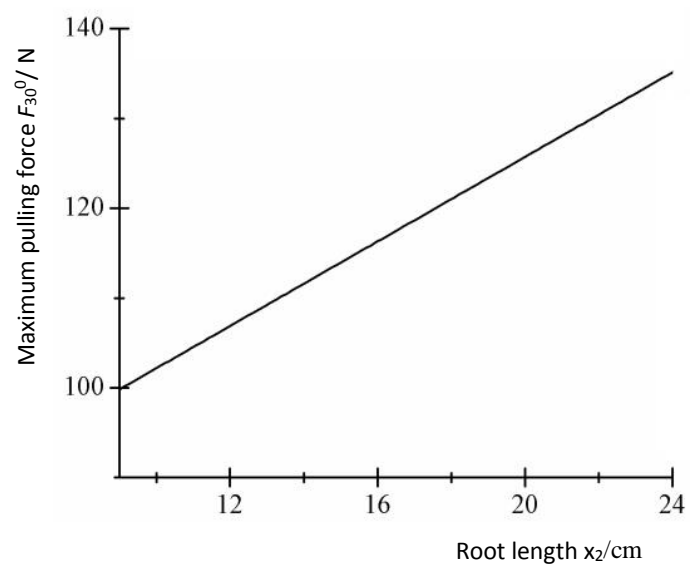

(b)

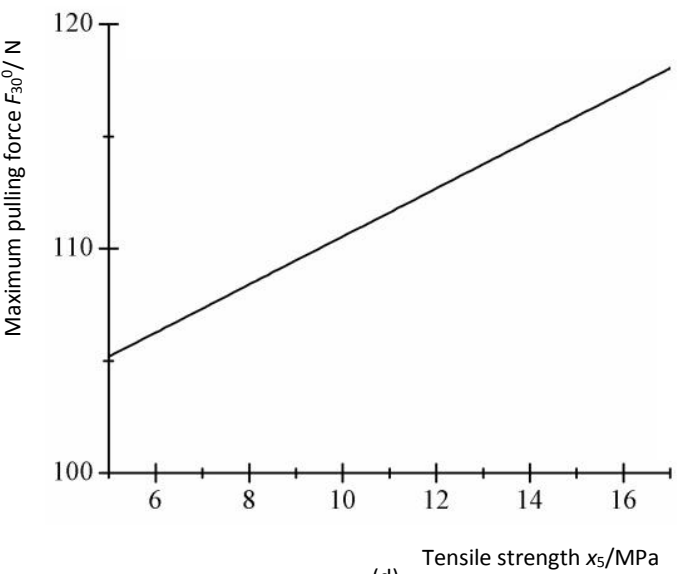

(d)

Figure 4. Relationship between factors and maximum pulling force $F_{30^{\circ}}$ 
Figure 4 shows that with the increase of number of roots, root length, root diameter and tensile strength of root, $F_{30}$ increases linearly and lodging resistance increases.

\section{Influence of factor interaction}

The relationships between $F_{30^{\circ}}$ and interaction of factors are shown in Figure 5.

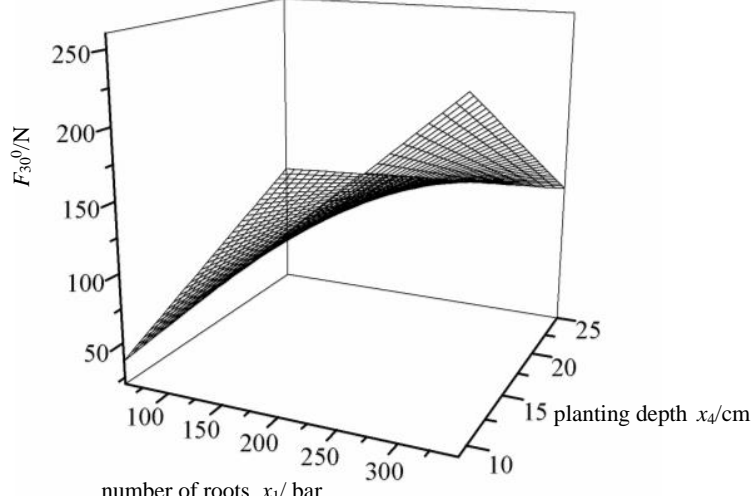

(a)

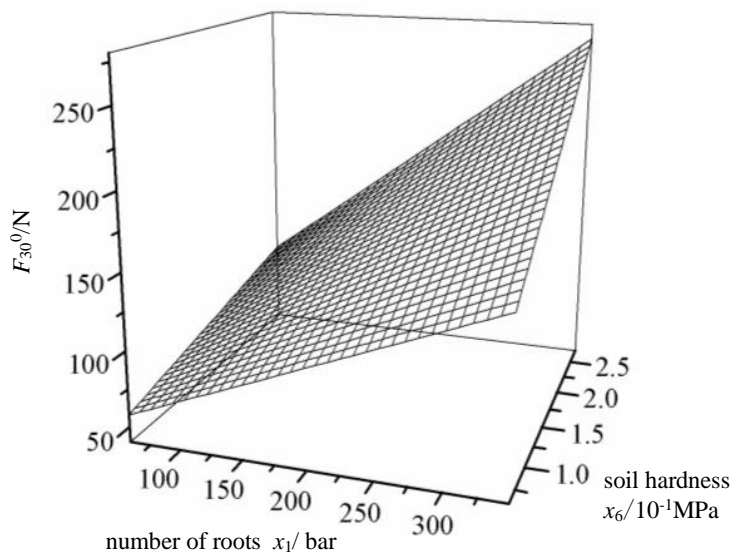

(c)

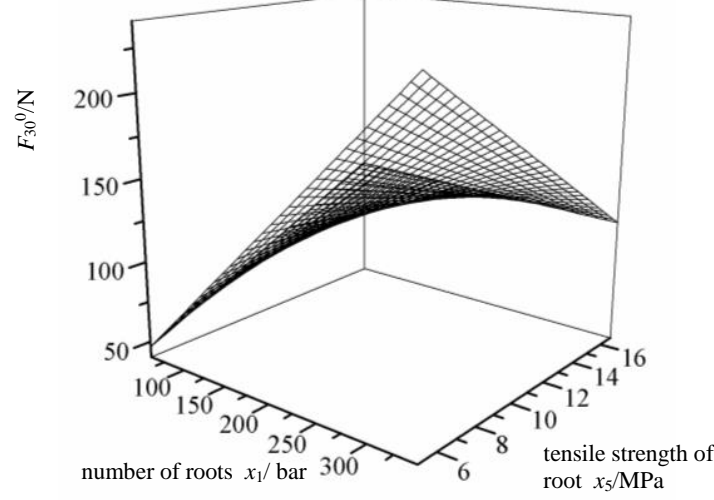

(b)

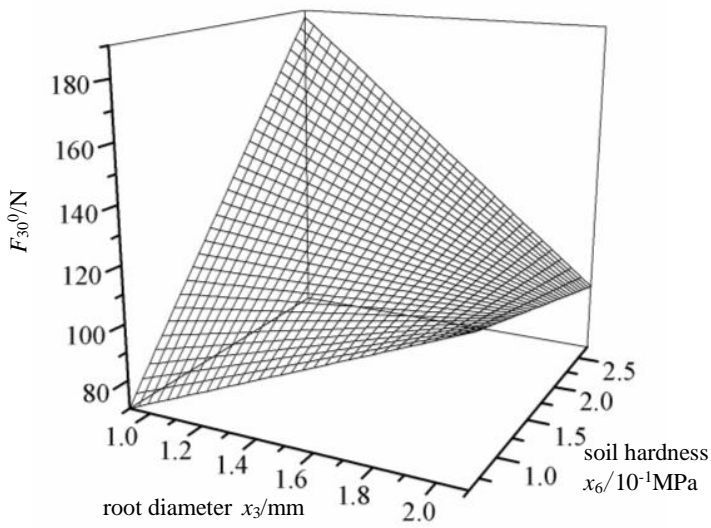

(d)

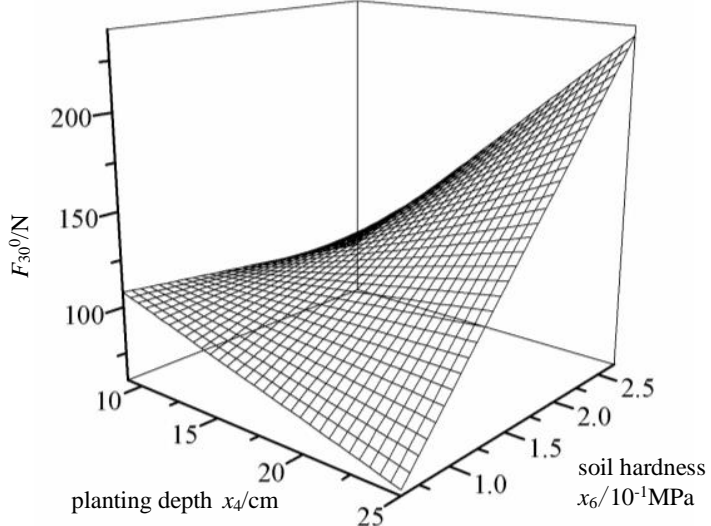

(e)

Figure 5. Relationship between interaction of factors and $F_{30^{\circ}}$

When number of roots is small, $F_{30^{\circ}}$ increases with the increasing of planting depth, while when number of roots is large, $F_{30^{\circ}}$ decreases with the increasing of planting 
depth. When planting depth is small, with the increasing of number of roots, $F_{30^{\circ}}$ increases, while when planting depth is large, with the increasing of number of roots, $F_{30^{\circ}}$ increases slowly (Fig. $5 a$ ).

When tensile strength of root is small, $F_{30}{ }^{\circ}$ increases with the increasing of number of roots, while when tensile strength of root is large, $F_{30} 0^{\circ}$ increases slowly with the increasing of number of roots. When number of roots is small, with the increasing of tensile strength of root, $F_{30}{ }^{\circ}$ increases, while when number of roots is large, with the increasing of tensile strength of root, $F_{30}{ }^{\circ}$ decreases (Fig. $5 b$ ).

Figure $5 c$ shows that $F_{30}{ }^{\circ}$ increases with the increasing of number of roots and soil hardness.

When soil hardness is small, $F_{30^{\circ}}$ increases with the increasing of root diameter, while when soil hardness is large, $F_{30^{\circ}}$ decreases with the increasing of root diameter. When root diameter is small, $F_{30^{\circ}}$ increases with the increasing of soil hardness, while when root diameter is large, $F_{30^{\circ}}$ decreases with the increasing of soil hardness (Fig. 5d).

When soil hardness is small, $F_{30^{\circ}}$ decreases with the increasing of planting depth, while when soil hardness is large, $F_{30^{\circ}}$ increases with the increasing of planting depth. When planting depth is small, $F_{30^{\circ}}$ decreases gently with the increasing of soil hardness, while when planting depth is large, $F_{30^{\circ}}$ increases with the increasing of soil hardness (Fig. 5e).

In the meantime, according to the above analysis, the order of factors affecting $F_{30^{\circ}}$ and Equation 1, we can obtain that when number of roots, root length, planting depth and soil hardness are at the maximum value, meanwhile, root diameter and tensile strength of root are at the minimum value, $F_{30^{\circ}}$ is the largest, and the maximum value is $378.3 \mathrm{~N}$.

\section{Discussion}

In this study, we obtained a mathematical model of the effect of multiple factors on lodging resistance of sugarcane, and the multiple factors include number of roots, root diameter, tensile strength of root, root length, planting depth and soil hardness. The order and the law of root-soil factors influencing the lodging resistance of sugarcane were clarified. And the most effective lodging resistance measure of sugarcane was proposed.

The mathematical model in this paper and the method using the model to study the influence of multiple factors on lodging resistance have not been reported in previous studies. The method can find out the order of the influence of root-soil factors on lodging resistance and analyze the influence of factor interaction on lodging resistance. The results of the effect of single factor on lodging resistance are consistent with the literature (Goodman and Ennos, 1999; Berry et al., 2000; Terashima et al., 2003; Berding and Hurney, 2005; Loades et al., 2013; Loganandhan et al., 2013; Manzur et al., 2014; Bian et al., 2016; Wu and Ma, 2018; Jongrungklang et al., 2018), while the effect of factor interaction on lodging resistance is complex.

\section{The effect of factor interaction on lodging resistance}

\section{Number of roots and planting depth}

When number of roots is small, the porosity of the root plate is relatively small. Although with the increasing of planting depth, the water penetrates downward and 
moisture content of the root plate increases slightly, which cause the resistance ability of deformation and shear decrease slightly. However, the center of gravity of the root plate moves downward and the supporting force's arm of sugarcane increases. Thus, for all the above reasons, $F_{30^{\circ}}$ increases. When number of roots is large, with the increasing of planting depth, the center of gravity of the root plate moves downward and the supporting force's arm of sugarcane increases. Nonetheless, moisture content of the root plate increases, and the resistance ability of deformation and shear decreases. Therefore, for all the above reasons, $F_{30^{\circ}}$ decreases.

With the increasing of number of roots, the root plate increases (Berry et al., 2000; Manzur et al., 2014; Bian et al., 2018; Wu and Ma, 2018). Furthermore, when planting depth is small, the moisture content of the root plate is small. Therefore, when planting depth is small, with the increasing of number of roots, although the porosity of the root plate also increases, but the moisture content maintains lower and the resistance ability of deformation and shear maintains stronger, $F_{30}$ increases. When planting depth is large, with the increasing of number of roots, although the root plate increases, but the moisture content increases and the resistance ability of deformation and shear decreases, thus, $F_{30^{\circ}}$ increases slowly.

\section{Number of roots and tensile strength of root}

The roots with low tensile strength are the new roots, which have strong growth vigor, more branches and root hairs (Fig. 6). The anchoring effect of a single root on soil is strong. Thus, when tensile strength of root is small, with the increasing of number of roots, the root plate increases, which cause $F_{30}{ }^{\circ}$ increases. And when tensile strength of root is large, with the increasing of number of roots, the dragging effect of roots increases, however, the root plate increases slowly, which cause $F_{30}{ }^{\circ}$ increases slowly.

The number of roots is small, the root plate is small (Wu and Ma, 2018). Therefore, when number of roots is small, with the increasing of tensile strength of root, although the root plate decreases slightly, but the dragging effect of roots increases, which cause $F_{30}{ }^{\circ}$ increases. And when number of roots is large, with the increasing of tensile strength of root, although the dragging effect of roots increased, but the root plate decreases, which cause $F_{30}{ }^{\circ}$ decreases.

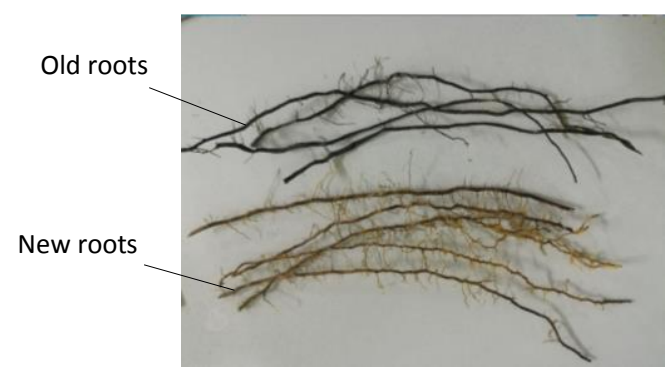

Figure 6. Sugarcane roots

\section{Number of roots and soil hardness}

When the number of roots is numerous and the soil hardness is large, the root plate is large, and the resistance ability of deformation and shear is strong, the lodging resistance is strong. It is consistent with the literatures (Goodman and Ennos, 1999; Loades et al., 2013). 


\section{Root diameter and soil hardness}

When soil hardness is small, the moisture content is high, and the adhesion and friction between roots and soils are large (within the range of the tested soil hardness). Therefore, when soil hardness is small, with the increasing of root diameter, the new roots turn into the old roots, although the root plate decreases relatively, however, the adhesion and friction between roots and soils increase, for all the above reasons, $F_{30^{\circ}}$ increases. And when soil hardness is large, the root plate decreases with the increasing of root diameter, and the adhesion and friction between roots and soils increase slowly, which cause $F_{30}$ decreases.

When root diameter is small, with the increasing of soil hardness, although the adhesion and friction between roots and soils decrease slightly, the resistance ability of deformation and shear of the root plate increases, result in the increase of $F_{30}$. And when root diameter is large, with the increasing of soil hardness, although the resistance ability of deformation and shear of the root plate increases, however, the adhesion and friction between roots and soils decreases, result in the decrease of $F_{30^{\circ}}$.

\section{Planting depth and soil hardness}

The soil hardness (the average value of three soil layers) is small, the moisture content is high. And moisture content can be higher in a deeper soil depth due to the downward infiltration of water. Therefore, when soil hardness is small, with the increasing of planting depth, although the supporting force arm of sugarcane increases, but the hardness of the lower part of the root plate decreases, result in the decrease of $F_{30^{\circ}}$. And when soil hardness is large, the hardness of the lower part of the root plate decreases slightly with the increasing of planting depth, but the supporting force arm of sugarcane increases, result in the increase of $F_{30^{\circ}}$.

When planting depth is small, the supporting force arm of sugarcane is small. Therefore, when planting depth is small, with the increasing of soil hardness, although the resistance ability of deformation and shear of the root plate increases and the stabilizing effect of sugarcane also increases slightly, nevertheless, the adhesion and friction between roots and soils decrease, result in the decrease of $F_{30}$. And when planting depth is large, with the increasing of soil hardness, although the adhesion and friction between roots and soils decrease, nevertheless, the resistance ability of deformation and shear of the root plate increases, and the stabilizing effect of sugarcane also increases, result in the increase of $F_{30}$.

\section{Lodging resistance measure}

Many scholars have studied the effects of number, length, growth depth and strength of roots, planting depth, soil hardness, drainage and fertilization on crop lodging resistance, and their results showed that when the planting depth, the soil hardness, and the number, length, growth depth and tensile strength of roots were large, the crop lodging resistance was strong, however, they did not indicate which of these factors has the greatest effect on crop resistance (Goodman and Ennos, 1999; Berry et al., 2000; Terashima et al., 2003; Berding and Hurney, 2005; Loades et al., 2013; Loganandhan et al., 2013; Manzur et al., 2014; Bian et al., 2016; Jongrungklang et al., 2018; Wu and Ma, 2018; Liu et al., 2018). And according to the research in this paper, we clarified the order of the influence of root-soil factors on the lodging resistance of sugarcane. And the order is number of roots and interaction between planting depth and soil hardness, 
root diameter and interaction between root diameter and soil hardness and interaction between number of roots and planting depth, tensile strength of root, interaction between number of roots and tensile strength of root, root length, interaction between number of roots and soil hardness. It shows that the number of roots and the interaction between planting depth of roots and soil hardness are the two most important influence factors of lodging resistance, meanwhile, our results show that when the number of roots, planting depth and soil hardness are large, lodging resistance is the greatest. Therefore, the most effective measure to improve the lodging resistance of sugarcane is to increase the number of roots through breeding and reasonable fertilization, and to increase the planting depth of sugarcane, meanwhile, to establish good drainage measures to timely drain water in typhoon season for reducing soil moisture and maintaining greater soil hardness.

\section{Conclusions}

In this study, a mathematical model of the effect of root-soil factors on lodging resistance of sugarcane was established by using field tilt test and regression analysis method. Using the model, the research on the influence of multiple factors on lodging resistance was carried out. The most important influence factors of lodging resistance and the influencing law of factor interaction on lodging resistance were clarified. And the most effective lodging resistance measure of sugarcane was proposed. In conclusion, we believe that the established mathematical model is reasonable. The change of sugarcane lodging resistance is the result of the comprehensive influence of number of roots, root diameter, tensile strength of root, root length planting depth and soil hardness. The two most important influence factors of sugarcane lodging resistance are number of roots and interaction between planting depth and soil hardness, while the influence of factor interaction on sugarcane lodging resistance is complex. The most effective measure to improve the lodging resistance of sugarcane is to increase the number of roots through breeding and reasonable fertilization, and to increase the planting depth of sugarcane, meanwhile, to establish good drainage measures to timely drain water in typhoon season for reducing soil moisture and maintaining greater soil hardness. Increasing the influence of root growth distribution on lodging resistance of sugarcane is the subject of future research.

Acknowledgements. This work was supported by a grant from the National Natural Science Foundation of China (Grant Nos 51565003 and 51365005), Guangxi Natural Science Foundation (Grant No. 2018GXNSFAA138196), Guangxi Key Laboratory of Manufacturing System \& Advanced Manufacturing Technology (Grant No. 17-259-05S006).

\section{REFERENCES}

[1] Babu, C., Koodalingam, K., Natarajan, U. S. (2009): Assessment of rind hardness in sugarcane (Sachharum Spp. Hybrids), genotypes for development of non lodging erect canes. - Advances in Biological Research 3(1-2): 48-52.

[2] Berding, N., Hurney, A. P. (2005): Flowering and lodging, physiological-based traits affecting cane and sugar yield. What do we know of their control mechanisms and how do we manage them. - Field Crops Research 92(2-3): 261-275. 
[3] Berry, P. M., Grifna, J. M., Sylvester-Bradley, R., Scott, R. K., Spink, J. H., Bakerd, C. J., Clare, R. W. (2000): Controlling plant form through husbandry to minimise lodging in wheat. - Field Crops Research 67: 59-81.

[4] Bian, D. H., Jia, G. P., Cai, L. J., Ma, Z. Y., Egrinya Eneji, A., Cui, Y. H. (2016): Effects of tillage practices on root characteristics and root lodging resistance of maize. - Field Crops Research 185: 89-96.

[5] Cao, Y. S., Chen, L. H., Liu, X. G., Yang, Y. J. (2014): The influence factors of plant roo-soil interface friction. - Tribology 34(5): 482-488.

[6] Chen, Z. D., Xiao, H. B., Zhang, C. X., Li, Z. Y., Zeng, J. J., He, B., Xie, J. Y. (2016): The impact of root distribution methods on the shear strength of root-soil composite. Journal of Central South University of Forestry \& Technology 36(8): 130-135.

[7] Goodman, A. M. and Ennos, A. R. (1999): The effects of soil bulk density on the morphology and anchorage mechanics of the root systems of sunflower and maize. Annals of Botany 83: 293-302.

[8] Jongrungklang, N., Maneerattanarungroj, P., Jogloy, S., Songsri, P., Jaisil, P. (2018): Understanding lodging resistant traits from diverse sugarcane lines. - Philippine Journal of Crop Science 43(2): 71-80.

[9] Kazuo, T., Takeshi, T., Hitoshi, O., Takayuki, U. (2003): Effect of field drainage on root lodging tolerance in direct-sown rice in flooded paddy field. - Plant Production Science 6(4): 255-261.

[10] Li, M., Tian, H. C., Huang, Z. G. (2017): Research on the development status of sugarcane industry in China. - Sugar Crops of China 39(1): 67-70.

[11] Li, X., Li, Y. J., Liang, Q., Lin, S. H., Huang, Q. Y., Yang, R. Z., Yang, L. T., Li, Y. R. (2019): Evaluation of lodging resistance in sugarcane (Saccharum spp. hybrid) germplasm resources. - Applied Ecology and Environmental Research 17(3): 6107-6116.

[12] Liu, S. Q., Song, F. B., Li, X. N., Wang, Y., Zhu, X. C. (2018): Effect of nitrogen application on nodal root characteristics and rootlodging resistance in maize. - Pakistan Journal of Botany 50(3): 949-954.

[13] Loades, K. W., Bengough, A. G., Bransby, M. F., Hallett, P. D. (2013): Biomechanics of nodal, seminal and lateral roots of barley: effects of diameter, waterlogging and mechanical impedance. - Plant Soil 370: 407-418.

[14] Loganandhan, N., Gujja, B., Goud, V. V., Natarajan, U. S. (2013): Sustainable Sugarcane Initiative (SSI): a methodology of "more with less". - Sugar Tech 15(1): 98-102.

[15] Manzur, M. E., Hall, A. J., Chimenti, C. A. (2014): Root lodging tolerance in Helianthus annuus (L.): associations with morphological and mechanical attributes of roots. - Plant Soil 381: 71-83.

[16] Mou, X. W., Xie, F. X., Ou, Y. G., Gong, J. H. (2010): Experiments of lifting process for the lodged sugarcane. - Journal of South China Agricultural University 31(3): 98-101.

[17] Ou, Y. G., Malcolm, W., Yang, D. T., Liu, Q. T., Zheng, D. K., Wang, M. M., Liu, H. C. (2013): Mechanization technology: the key to sugarcane production in China. International Journal of Agricultural and Biological Engineering 6(1): 1-27.

[18] Ren, L. Q. (2011): Soil Adhesion Mechanics. - Machinery Industry Press, Beijing.

[19] Singh, G., Chapman, S. C., Jackson, P. A., Lawn, R. J. (2002): Lodging reduces sucrose accumulation of sugarcane in the wet and dry tropics. - Australian Journal of Agricultural Research 53(11): 1183-1195.

[20] Sposaro, M. M., Chimenti, C. A., Hall, A. J. (2008): Root lodging in sunflflower. Variations in anchorage strength across genotypes, soil types, crop population densities and crop developmental stages. - Field Crops Research 106(2): 179-186.

[21] van Heerden, P. D. R., Singels, A., Paraskevopoulos, A., Rossler, R. (2015): Negative effects of lodging on irrigated sugarcane productivity - an experimental and crop modelling assessment. - Field Crops Research 180: 135-142. 
[22] Wang, W. Z., Fang, F. X., Zhu, Q. Z., Liang, T and Luo, Y. W. (2010): Discussion on key agronomic coordinated technology of sugarcane mechanical harvest. - Chinese Agricultural Mechanization 5: 63-67.

[23] Wang, X. Q., Zhang, J. (2018): Supporting policies and related development ideas of sugarcane industry in China. - Agricultural Outlook 14(1): 43-48, 53.

[24] Wu, W., Ma, B. L. (2018): Assessment of canola crop lodging under elevated temperatures for adaptation to climate change. - Agricultural and Forest Meteorology 248: 329-338.

[25] Yang, W., Zhang, S., Yang, J., Zhou, J., Lu, H. (2015): Experimental study on soil hardness of cultivated horizon at cassava cultivated farm in harvesting period. - Journal of Agricultural Mechanization Research 37(7): 176-180.

\section{APPENDIX}

Table A1. Test scheme and results

\begin{tabular}{|c|c|c|c|c|c|c|c|}
\hline $\begin{array}{c}\text { Test } \\
\text { number }\end{array}$ & $\begin{array}{c}\text { Number of } \\
\text { roots } \\
x_{1} / \text { bar } \\
\end{array}$ & $\begin{array}{c}\text { Root length } \\
x_{2} / \mathrm{cm}\end{array}$ & $\begin{array}{c}\text { Root } \\
\text { diameter } \\
x_{3} / \mathrm{mm}\end{array}$ & $\begin{array}{c}\text { Planting } \\
\text { depth } \\
x_{4} / \mathrm{cm}\end{array}$ & $\begin{array}{c}\text { Tensile } \\
\text { strength of root } \\
x_{5} / \mathrm{MPa}\end{array}$ & $\begin{array}{c}\text { Soil hardness } \\
x_{6} / 10^{-1} \mathrm{MPa}\end{array}$ & $\begin{array}{c}\text { Maximum } \\
\text { pulling force } \\
F_{30} / \mathbf{N} \\
\end{array}$ \\
\hline 1 & 87 & 11.98 & 1.67 & 15.5 & 11.76 & 0.79 & 76.51 \\
\hline 2 & 117 & 23.74 & 1.59 & 17 & 15.26 & 2.4 & 152.67 \\
\hline 3 & 81 & 15.43 & 1.89 & 11.8 & 6.55 & 0.89 & 80.65 \\
\hline 4 & 97 & 12.76 & 1.94 & 16.6 & 8.44 & 1.2 & 93.38 \\
\hline 5 & 66 & 14.4 & 2.10 & 16.2 & 9.55 & 0.76 & 78.92 \\
\hline 6 & 88 & 11.49 & 1.62 & 17.9 & 8.01 & 0.9 & 85.31 \\
\hline 7 & 141 & 12.10 & 1.66 & 22 & 8.29 & 0.65 & 72.5 \\
\hline 8 & 119 & 15.00 & 1.75 & 17 & 8.94 & 1.5 & 115 \\
\hline 9 & 77 & 14.50 & 1.41 & 19.5 & 11.91 & 0.73 & 88.5 \\
\hline 10 & 238 & 16.40 & 1.2 & 10.5 & 6.25 & 1.28 & 176.44 \\
\hline 11 & 195 & 13.80 & 1.62 & 17.5 & 7.37 & 1.23 & 125.8 \\
\hline 12 & 138 & 13.20 & 1.65 & 21 & 7.5 & 0.9 & 102.65 \\
\hline 13 & 215 & 14.80 & 1.34 & 17 & 7.21 & 0.72 & 108.14 \\
\hline 14 & 142 & 10.10 & 1.55 & 15.5 & 5.87 & 2 & 105.72 \\
\hline 15 & 136 & 11.40 & 1.34 & 13 & 8.33 & 1.8 & 102.72 \\
\hline 16 & 159 & 11.60 & 1.22 & 15.5 & 6.19 & 0.61 & 74.48 \\
\hline 17 & 61 & 9.04 & 1.11 & 19.5 & 10.4 & 0.92 & 65.6 \\
\hline 18 & 180 & 12.60 & 0.92 & 17.5 & 8.73 & 1.07 & 94.38 \\
\hline 19 & 179 & 16.30 & 1.32 & 13.5 & 10.61 & 1.22 & 180.44 \\
\hline 20 & 199 & 12.50 & 1.22 & 14 & 10.27 & 1.66 & 169.5 \\
\hline 21 & 77 & 16.10 & 1.01 & 18.2 & 11.1 & 1.21 & 94.3 \\
\hline 22 & 179 & 10.50 & 1.18 & 12.5 & 8.05 & 0.67 & 91.97 \\
\hline 23 & 119 & 10.30 & 1.75 & 25 & 9.06 & 1.25 & 128.59 \\
\hline 24 & 285 & 12.30 & 1.75 & 18.5 & 6.81 & 2.7 & 226.39 \\
\hline 25 & 209 & 16 & 1.39 & 14 & 12.48 & 1.3 & 128.59 \\
\hline 26 & 97 & 11.8 & 1.1 & 14.5 & 13.64 & 1.22 & 103.54 \\
\hline 27 & 156 & 14.5 & 1.24 & 13 & 8.99 & 1.07 & 105.31 \\
\hline 28 & 170 & 14.5 & 1.13 & 12.5 & 9.16 & 1.53 & 128.64 \\
\hline 29 & 153 & 10.6 & 1.07 & 13 & 5.88 & 1.6 & 105.32 \\
\hline 30 & 151 & 9.25 & 1.13 & 20 & 7.43 & 1.09 & 88.69 \\
\hline 31 & 221 & 11.4 & 1.03 & 14.5 & 5.06 & 2.02 & 192.13 \\
\hline 32 & 238 & 12.6 & 1.14 & 19 & 6.07 & 1.37 & 150.92 \\
\hline 33 & 347 & 16.5 & 1.3 & 18.5 & 9.33 & 2.44 & 257.84 \\
\hline 34 & 273 & 13.2 & 1.1 & 12.5 & 12.07 & 1.44 & 145.6 \\
\hline 35 & 98 & 11.5 & 1.04 & 11.5 & 10.92 & 0.92 & 75.5 \\
\hline
\end{tabular}




\begin{tabular}{l|c|c|c|c|c|c|c}
36 & 221 & 12.2 & 0.98 & 16 & 7.69 & 1.84 & 191.1 \\
37 & 149 & 13.8 & 1.23 & 12 & 11.18 & 1.44 & 105.89 \\
38 & 119 & 10.9 & 1.16 & 12.5 & 16.78 & 1.11 & 105.55 \\
39 & 150 & 9.68 & 1.32 & 9 & 6.47 & 1.64 & 75.25 \\
40 & 183 & 9.62 & 1.23 & 18 & 8.5 & 1.99 & 118.52 \\
41 & 121 & 10.6 & 1.34 & 17.5 & 7.19 & 1.07 & 92.08 \\
42 & 58 & 14.8 & 1.27 & 13 & 9.5 & 1.73 & 71.63 \\
43 & 81 & 13.5 & 1.2 & 17 & 7.2 & 0.86 & 46.46 \\
44 & 64 & 11.9 & 1.43 & 12.3 & 8.6 & 1.28 & 51.94 \\
45 & 87 & 17.3 & 1.97 & 17.5 & 8.97 & 1.49 & 87.65 \\
\hline
\end{tabular}

